\title{
A Study to Assess Knowledge Regarding Prevention and Home Care Management of Diarrhea among Mothers of Under-Five Children Attending a Tertiary Level Hospital, Thiruvananthapuram, Kerala
}

\author{
Ancey K Toby ${ }^{1}$, Aruna $R^{2}$, Avani Anil ${ }^{3}$, Nimmy John ${ }^{4}$, Rakhi S R $\mathbf{R}^{5}$, \\ Sariga T S ${ }^{6}$, Tigi Abraham ${ }^{7}$, Jyothis Prakash ${ }^{8}$, Aswathy K L ${ }^{9}$ \\ ${ }^{1-7}$ BSc Nursing, ${ }^{8}$ Lecturer, ${ }^{9}$ Assistant Professor, \\ Government College of Nursing, Medical College, Thiruvananthapuram, Kerala
}

Corresponding Author: Jyothis Prakash

\begin{abstract}
Aim: To find out the knowledge level of mothers of under five children regarding prevention and home care management of diarrhea and develop educational intervention to provide them adequate information regarding management.
\end{abstract}

Objectives:

i) To assess the knowledge of mothers regarding prevention and home care management of diarrhea.

ii) To find out the association between knowledge level of mothers regarding prevention and homecare management of diarrhea and selected socio-demographic variables.

Method: A quantitative research approachdescriptive cross-sectional survey design was adopted. 80 samples were selected for the study by using purposive sampling technique.

Results: It was found that $72.5 \%$ of mothers had average knowledge and $6.25 \%$ of mothers had poor knowledge regarding prevention and homecare management of diarrhea. After calculation of chi square values, it is identified that there is a statistically significant association between knowledge of mothers and their educational status.

Conclusion: The finding of this study showed that the knowledge level of mothers was unsatisfactory about the prevention and home care management of under-five diarrheal diseases. Therefore, health education, dissemination of information, and community conversation should plan and implement to create a positive attitude and practice towards the better prevention and management of underfive diarrheal diseases.

Keywords: diarrhea, mothers, under-five children.

\section{INTRODUCTION}

Infections or communicable diseases are those caused from pathological organisms including bacteria, virus, fungi, parasites etc, which can spread from one person to another by direct or indirect means. Infectious diseases are the major cause of death in developing nations. In the year 1993, about 51 million people died in UK out of which 16.4 million (35\%) were from infectious diseases. ${ }^{1}$

Among the infectious diseases, diarrhea is the second leading killer of under-five children. Each year an estimated 2.5 billion cases of diarrhea occur among children under five years of age. More than half of these cases are in Africa and South Asia, where bouts of diarrhea are more likely to result in death of severe outcomes. ${ }^{2}$ Diarrhea is the major public health problem in developing countries. In developing 
countries 4.9 children per thousand per year die as a result of diarrheal illness in the first five years of life. ${ }^{3}$

The under-five mortality rate in India is 76 per 1000 live births. ${ }^{4}$ The present study aimed to assess knowledge regarding prevention and home care management of diarrhea among mothers of under-five children attending Sree Avittom Thirunal Hospital, Thiruvananthapuram, Kerala.

\section{LITERATURE REVIEW}

Diarrhea is one of the leading causes of death and illness among children of under-five years of age in the world. ${ }^{5}$ In 2013, over 570,000 children under five years of age died from dairrhea. ${ }^{6}$

In India, diarrhea caused more than 130,000 child deaths in $2013 .^{7}$ This accounts for roughly one fourth of all global diarrhea deaths among children under five years of age. $^{8}$

According to WHO, Passage of 3 or more than 3 loose of stool or watery stools per day or considers as abnormal by the mothers or stools more frequent than normal for a child is considered as diarrhea. ${ }^{9}$

Contaminated weaning food, inappropriate feeding practice, lack of clean water, poor hand washing, limited sanitary disposal of waste, poor housing conditions, and lack of access to adequate and affordable health care are aggravated factors of the under 5 diarrheal disease. ${ }^{10}$

A study conducted in urban field practice area of MRMC, Kalaburagi, Karnataka showed that half of participants lacked adequate knowledge regarding danger signs, spread and prevention of diarrheal diseases among children. Poor dietary practices were prevalent among $50.49 \%$ of mothers. Only $50.49 \%$ mothers practiced exclusive breast feeding. Nearly $1 / 5^{\text {th }}$ of mothers practiced bottle feeding, among them only $26.82 \%$ practiced hygienic measures. (55.88\%) dispose feces in open air. Only $93.62 \%$ mothers demonstrated proper technique of hand washing. $86.27 \%$ participants knew about ORS, among them more than half had adequate knowledge regarding preparation and administration. ${ }^{11}$

A hospital based cross sectional study was carried out in the pediatric outpatient department, Agartala Government Medical College and GB Pant Hospital, Agartala, Tripura with a sample size of 700 mothers of under five children over 2 months. Convenience sampling technique was employed and the data were collected in a structured interview schedule. This study was conducted with an objective of assessing knowledge and practice of mothers of under-five children about zinc supplementation in diarrhea. The study affirmed the profoundly low level of awareness about zinc supplementation among mothers. Only $1.9 \%$ of all the respondents had heard about zinc therapy in diarrhea. Out of them, 11 mothers had actually used zinc in practice and 7 could tell the duration of therapy. None of them were aware of what benefit is considered by zinc in an episode of diarrhea. The study concluded that health education can be used as a tool to promote knowledge and practice of zinc supplementation in diarrhea to reduce mortality and morbidity. ${ }^{12}$

A study was conducted on mothers' beliefs and practices regarding prevention and management of diarrheal disease at Chandigarh, India. About 48 mothers with child aged less than 5 years in the 2 villages were interviewed. The study result showed that only $10.4 \%$ knew specific ways to prevent diarrhea; $50 \%$ believed less fluids than the normal amount should be given during diarrhea, $68.8 \%$ would administer home remedies to treat diarrhea and $18.8 \%$ would begin oral rehydration therapy at home, $54 \%$ had used oral rehydration solution in the past. $42.9 \%$ of them knew how to prepare correctly and $70.5 \%$ knew how to administer it correctly. The study concluded that the need to focus on preventive measures by educating the mothers about causes and methods of prevention of diarrhea. ${ }^{13}$ 
MATERIALS \& METHODS

Research Approach: A quantitative research approach-descriptive crosssectional survey design was adopted.

Setting of the Study: The study was conducted in the pediatric wards and outpatient department of Sree Avitham Thirunal Hospital, Thiruvanathapuram, Kerala. Sree Avittam Thirunal Hospital is a tertiary care referral hospital under Government sector, where most of the patients are referred cases from community.

\section{Sampling Technique and Sample Size:}

Purposive sampling technique was used in this study to select the mothers of under five children and present study sample size consists of 80 mothers from pediatric wards and outpatient department.

\section{Sampling Criteria:}

- Inclusion Criteria:

1. Mothers of children less than 5 years of age.

2. Mothers of children admitted with any disease in SAT Hospital.

3. Mothers of children consulting in SAT Hospital OPD.

- Exclusion Criteria: Mothers of children who were critically ill.

Data Collection Techniques: Tool used in this study was structured interview schedule consisted of two parts.

- Part I: Socio demographic data, which includes age, religion, education, socioeconomic status, source of water and sanitation.

- Part II: Questions to assess the knowledge regarding prevention and home care management of diarrhea.

Total score: 39

Scoring: According to the score obtained by the subjects we classify them as, Good : 27-39 [69-100\%]

Average : 14-26 [35-69\%]

Poor : $1-13[<35 \%]$

\section{Statistical Analysis}

The data collected was entered in a Microsoft excel spreadsheet. Continuous variables were summarized as means and standard deviation, and categorical variables were summarized as percentages. ChiSquare test was used to find out association between knowledge and selected sociodemographic variables. A p-value of $<0.05$ was taken as statistically significant.

\section{RESULT}

The data was collected from 80 mothers of under five children attended Sree Avitom Thirunal Hospital, were tabulated, analysed and interpreted using descriptive and inferential statistics. Knowledge of mothers was analysed using mean and standard deviation. Knowledge of mothers and its association with socio demographic variable was analysed in terms of chi-square test. The results have been presented below in tabular and graphical forms.

\section{Section 1: Socio-demographic data of} mothers of under five children.

Table 1: Socio-demographic characteristics of mothers $(n=80)$

\begin{tabular}{|c|c|c|}
\hline Age & Number & Percentage $(\%)$ \\
\hline $20-24$ & 15 & 18.75 \\
\hline $25-29$ & 42 & 52.5 \\
\hline $30-34$ & 21 & 26.25 \\
\hline $35-39$ & 2 & 2.5 \\
\hline \multicolumn{3}{|l|}{ Religion } \\
\hline Hindu & 55 & 68.75 \\
\hline Christian & 13 & 16.25 \\
\hline Muslim & 12 & 15 \\
\hline \multicolumn{3}{|l|}{ Type of Family } \\
\hline Nuclear & 51 & 63.75 \\
\hline Extended & 28 & 35 \\
\hline Joint & 1 & 1.25 \\
\hline \multicolumn{3}{|l|}{ Monthly Income } \\
\hline Above poverty line & 21 & 26.25 \\
\hline Below poverty line & 59 & 73.75 \\
\hline \multicolumn{3}{|l|}{ Number of Family Members } \\
\hline$\leq 5$ & 57 & 71.25 \\
\hline$\geq 5$ & 23 & 28.75 \\
\hline \multicolumn{3}{|l|}{ Educational Status } \\
\hline No formal education & 2 & 2.5 \\
\hline Primary education & 8 & 10 \\
\hline Upper primary education & 1 & 1.25 \\
\hline High school education & 11 & 13.75 \\
\hline Pre-degree education & 26 & 32.5 \\
\hline Diploma/Degree education & 32 & 40 \\
\hline \multicolumn{3}{|c|}{ Number of Under Five Children } \\
\hline 1 & 53 & 66.25 \\
\hline 2 & 22 & 27.5 \\
\hline$\geq 3$ & 5 & 6.25 \\
\hline \multicolumn{3}{|l|}{ Source of Water Supply } \\
\hline Well & 64 & 80 \\
\hline Tap & 15 & 18.75 \\
\hline Pond & 0 & 0 \\
\hline Public well & 1 & 1.25 \\
\hline \multicolumn{3}{|l|}{ Method of Excreta Disposal } \\
\hline Latrine & 80 & 100 \\
\hline Open spaces & 0 & 0 \\
\hline
\end{tabular}




\section{Section 2: Analysis of knowledge of mothers regarding prevention and homecare management of diarrhea in under-five children.}

Table 2: Mean and standard deviation of knowledge regarding prevention and home care management of diarrhea $\mathrm{N}=80$

\begin{tabular}{|c|c|c|}
\hline Samples & Mean & Standard deviation \\
\hline 80 & 21.51 & \pm 5.72 \\
\hline
\end{tabular}

Average knowledge of mothers regarding prevention and home care management of diarrhea is $21.51 \pm 5.72$.

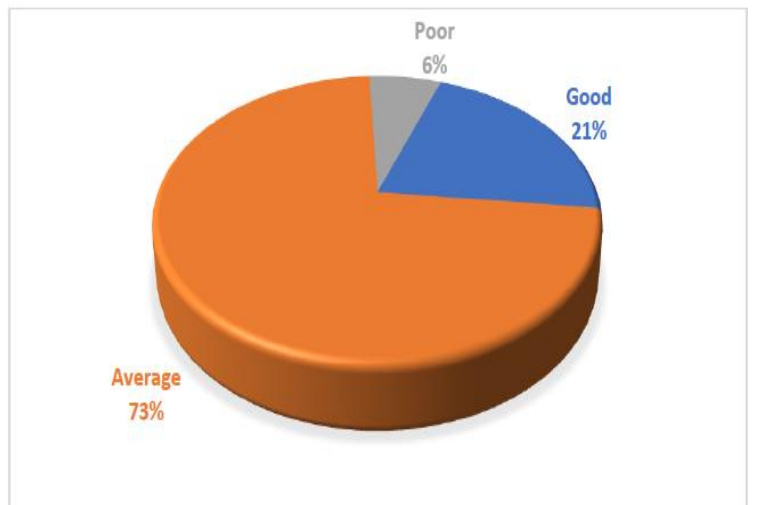

Figure 1: Distribution of mothers based on their level of knowledge $\quad \mathrm{N}=\mathbf{8 0}$

Above figure shows that $21.25 \%$ of mothers had good knowledge, $72.5 \%$ had average knowledge and $6.25 \%$ had poor knowledge.

Section 3: Association of knowledge and selected socio-demographic variable. $\mathrm{N}=80$

\begin{tabular}{|l|c|c|c|}
\hline \multicolumn{1}{|c|}{ Variables } & $\begin{array}{c}\text { df } \\
\text { value }\end{array}$ & $\begin{array}{c}\text { Chi square } \\
\text { value }\end{array}$ & Table value \\
\hline Age & 1 & 0.449 & 3.84 \\
\hline Religion & 2 & 3.178 & 5.99 \\
\hline Educational status & 2 & $9.45^{*}$ & 5.99 \\
\hline
\end{tabular}

In the case of educational status of mothers, the calculated chi-square value is higher than the table value at $\mathrm{p}<0.05$, there is significant association between educational status and knowledge of mothers regarding prevention and home care management of diarrhea in under-five children $\left(\chi^{2}=9.45, \mathrm{df}=2\right)$.

\section{DISCUSSION}

The present study was focused on assessment of knowledge regarding prevention and home care management of diarrhea among mothers of under-five children.
In the present study, it was found that $52.5 \%$ of mothers belong to the age group of 25-29years. It was consistent with the finding of the study conducted in Kashan, Iran. It revealed that among 430 samples most of the mothers belong to the age group of 25-30 years. ${ }^{14}$

In the present study, it was found that $72.5 \%$ of mothers had average knowledge and $6.25 \%$ of mothers had poor knowledge regarding prevention and homecare management of diarrhea. It was consistent with a study conducted in Waghodia village in Gujarat, India. The study population was the mothers of underfive children. The study showed that only $44 \%$ had average knowledge and the rest had poor knowledge regarding prevention and home management of diarrhea. It also showed a significant association between education of mothers and their knowledge. ${ }^{15}$

The findings of the study were consistent with the findings of the study conducted in Haryana, India. The study sample was 145 rural mothers of the district and the result showed that only $29 \%$ of mothers knew about the preparation and administration of ORS and the knowledge regarding management of diarrhea. ${ }^{16}$

Another study conducted in urban slums of Aligarh, India revealed that less than half of the mothers $(46.5 \%)$ know about ORS and other home management of diarrhea. ${ }^{17}$

Contradictory to the findings obtained in the present study, a study conducted in Amhara Regional State, Northwest Ethiopia revealed that majority (63.6\%) of mothers had good knowledge towards diarrhea management and $45.9 \%$ had good practice. ${ }^{18}$

Contradictory to the findings of the present study, a descriptive cross-sectional study conducted in rural community of South Nigeria showed that $60.8 \%$ were graded having poor knowledge. But the study showed significant association of knowledge with age, educational level and socioeconomic status of mothers. ${ }^{19}$ 


\section{CONCLUSION}

The finding of this study showed that the knowledge of mothers were unsatisfactory about the prevention and home care management of under-five diarrheal diseases. Therefore, health education, dissemination of information, and community conversation should plan and implement to create a healthy knowledge for the better prevention and management of under five diarrheal diseases.

\section{Acknowledgement: None}

\section{Conflict of Interest: None}

\section{Source of Funding: None}

\section{Ethical Approval: Approved}

\section{REFERENCES}

1. Mary E Wilson. Travel and the emergence of infectious diseases. Emerging infectious diseases.1995:12(2);39-43

2. Boschi Pinto C. The Global Burden of childhood Diarrhea in Ehiri. International Maternal and Child Health .2009.10;25-29

3. UNICEF, Survey of 10 districts. Management practices of childhood diarrhea in India, New Delhi: UNICEF; 2009.

4. World Health Organisation, Geneva: Diarrheal Disease: Fact sheet No,330, World Health Organisation; 2013[cited 2014 September 11], Available from: http//www.who.int/mediacentre/factsheets/I s330/en/intex.html

5. Fischer Walker C, Rudan I, Liu L. Global Burden of Childhood Pneumonia and Diarrhea, Lancet 2013

6. Committing to Child Survival: A Promise Renewed Progress Report 2014, UNICEF [2014]. Available from URL: http://files.unicef.org/publications/ files/AFR 2014

7. Liu L. Global Regional and National Causes of Child Mortality in 2000-13 with projections to inform post-2015 priorities: An updated systematic analysis. Lancet[2014] Available from URL: http://www.thelancet.com/journals/lancet/art icle/P1150140-6736[14]61698-6
8. Park K, Acute Diarrheal Diseases, Inc Textbook of Preventive and Social Medicine $22^{\text {nd }}$ ed, Jabedpur, M/s Benarsidas Bharot Publishers;2013, P.200-3.

9. WHO, UNICEF. WHO-UNICEF joint statement on the clinical management of acute diarrhea. Geneva: World Health Assembly; 2004.

10. World Health Organization. Diarrhoeal disease Fact sheet $\mathrm{N}^{\circ} 330.2013$ [Available from: https://web.archive.org/web/2014071 7205014/http://www.who.int/mediacentre/fa ctsheets/fs330/en/]. Accessed 15 May 2016.

11. Kiran Kumar Rokkapanavar SR, Nigudgi, Shreeshali Ghooli, A study on knowledge and practice of mothers of under five children regarding management of diarrhea in urban field practice area of MRMC, Kalaburagi, Karnataka, India. International Journal of Community Medicine and Public Health.2016 March; 3 (3):705-710.

12. Gorelick MH, Shah KN, Murphy KO. Validity and reliability of clinical signs in the diagnosis of dehydration in children. PMID; 12187057 (pubmed-index for MEDLINE)

13. Ahmed I S, Eltom A R, Karrar Z A, Gibril A R. Knowledge attitude and practice of mother regarding diarrhea among children in a Sudaness rural community. East African medical journal ISSN 0012-835X 1994 Vol 71, pp.716-719.

14. Amir AbdollahGhaseni, AhamadTelebian, Negin Masoudi Alavi, Gholam Abbas Mousavi. Knowledge of mothers in management of diarrhea in under-five children in Kashan, Iran; nms journal [pubmed] Nursing and midwifery studies 2013 March; 1(3) 158-62

15. Nirmal Raj, Rajesh, Akshay Vyas, Amin Hetal, Binita Patel, Rajan Chauhan, Shekha Chauhan, et al. A study to assess the knowledge regarding prevention and management of diarrhea among mothers of under five children residing in selected villages of Waghodia, Taluka: Indian journal of applied research volume 6 issue 8 Aug 2016 408-410

16. Anand K, Lobo J, Sundaran KR, Kapoor SK. Knowledge and practice regarding diarrhea in rural mothers of Haryana. Indian Pediatr.2002 Jul; 29 (7); 914-7.

17. Mohammed Salman Shah, Anees Ahamad, Najam Khalique, Subooli Afzal, Mohammad Athar Ansari, Zulfia Khan; 
Ancey $K$ Toby et.al. A study to assess knowledge regarding prevention and home care management of diarrhea among mothers of under-five children attending a tertiary level hospital, Thiruvananthapuram, Kerala

Home based management of acute diarrheal disease in an urban slum of Aligarh , India; J Infect DevCtries 2012;6(2):137-142

18. Desalegne Amare, Birtukan Dereje, Berhanu Kassie, Minchi Tessema, Getachew Mullu, Bekalu Alene et al; Maternal knowledge and practice towards diarrhea management in under five children in Fenote Selam Town, Amhara Regional State North west Ethiopia 2014 journal of infectious disease and therapy 2:182

19. Tobin EA, Isah EC, Asogun DA. Caregivers knowledge about childhood diarrheal management in a rural community in South
Nigeria; International journal of community research 2014; 3(4):93-99.

How to cite this article: Toby AK, Aruna R, Anil A et.al. A study to assess knowledge regarding prevention and home care management of diarrhea among mothers of under-five children attending a tertiary level hospital, Thiruvananthapuram, Kerala. International Journal of Science \& Healthcare Research. 2021; 6(3): 466-471. DOI: https:// doi.org/10.52403/ijshr.20210775 